\title{
Differing Trends in the Tropical Surface Temperatures and Precipitation over Land and Oceans
}

\author{
ARUN KUMAR \\ NOAA/Climate Prediction Center, Camp Springs, Maryland \\ FANGLIN YANG \\ NASA GSFC, Greenbelt, Maryland \\ LISA GODDARD \\ Forecast Division, IRI, Palisades, New York \\ SIEGFRIED SCHUBERT \\ Data Assimilation Office, NASA GSFC, Greenbelt, Maryland
}

(Manuscript received 16 January 2003, in final form 18 June 2003)

\section{ABSTRACT}

\begin{abstract}
In the past 50 years, sea surface temperatures (SSTs) in the tropical latitudes have trended toward a warmer ocean state. As a response, tropical land surface temperatures, as well as tropical tropospheric temperatures (as manifested in the variations in the 200-mb tropical heights), have also trended upward. Analysis of trends in the tropical precipitation fields, however, remains problematic because of the scarcity of the observed data over the tropical oceans.

Using both observed data and data from atmospheric general circulation model simulations, trends in tropical precipitation over the ocean and land are analyzed. The analysis reveals that in the tropical latitudes over land, the precipitation trend differs from the trend in the surface temperature. Oceanic precipitation has an increasing trend that is consistent with increasing SSTs, whereas over the tropical land regions precipitation decreases. In contrast, land temperatures increase in phase with the trend in SSTs. It is suggested that the combination of increasing surface temperature and decreasing precipitation could produce considerably greater societal consequences compared with the traditionally argued scenario in which both temperature and precipitation increase in response to increasing SSTs.
\end{abstract}

\section{Introduction}

During the last 50 years, sea surface temperatures (SSTs) over the tropical oceans have trended upward (Fig. 1, top panel). Regardless of whether this trend is a consequence of anthropogenic activity or is due to a long-term natural variability in the oceans, the warmer tropical SSTs are likely to influence the atmospheric circulation on a global scale. This expectation is based on the fact that such atmospheric influences occur on interannual time scales, for example, the global atmospheric teleconnections associated with the interannual variability of the tropical Pacific SSTs related to ENSO

Corresponding author address: Dr. Arun Kumar, Climate Prediction Center, NOAA/NWS/NCEP, 5200 Auth Road, Rm. 800, Camp Springs, MD 20746.

E-mail: arun.kumar@noaa.gov (see Trenberth et al. 1998; Hoerling and Kumar 2002, for recent reviews).

The atmospheric response to SST trends in variables like temperature and height can be inferred from the observed data with confidence [e.g., National Centers for Environmental Prediction-National Center for Atmospheric Research (NCEP-NCAR) reanalysis data, Kalnay et al. 1996]; however, the SST influence on precipitation is much harder to estimate. On the one hand, direct measurements of precipitation over the oceanic regions are not available, while on the other, precipitation estimates from the reanalysis data are not always reliable due to inadequate analysis of divergent circulation (Sardeshmukh 1993). There are now possibly reliable satellite-based estimates over the oceans, but the length of the satellite precipitation record is still too short to be useful for trend analysis (Huffman et al. 1997).

It has been argued that total precipitation will increase 

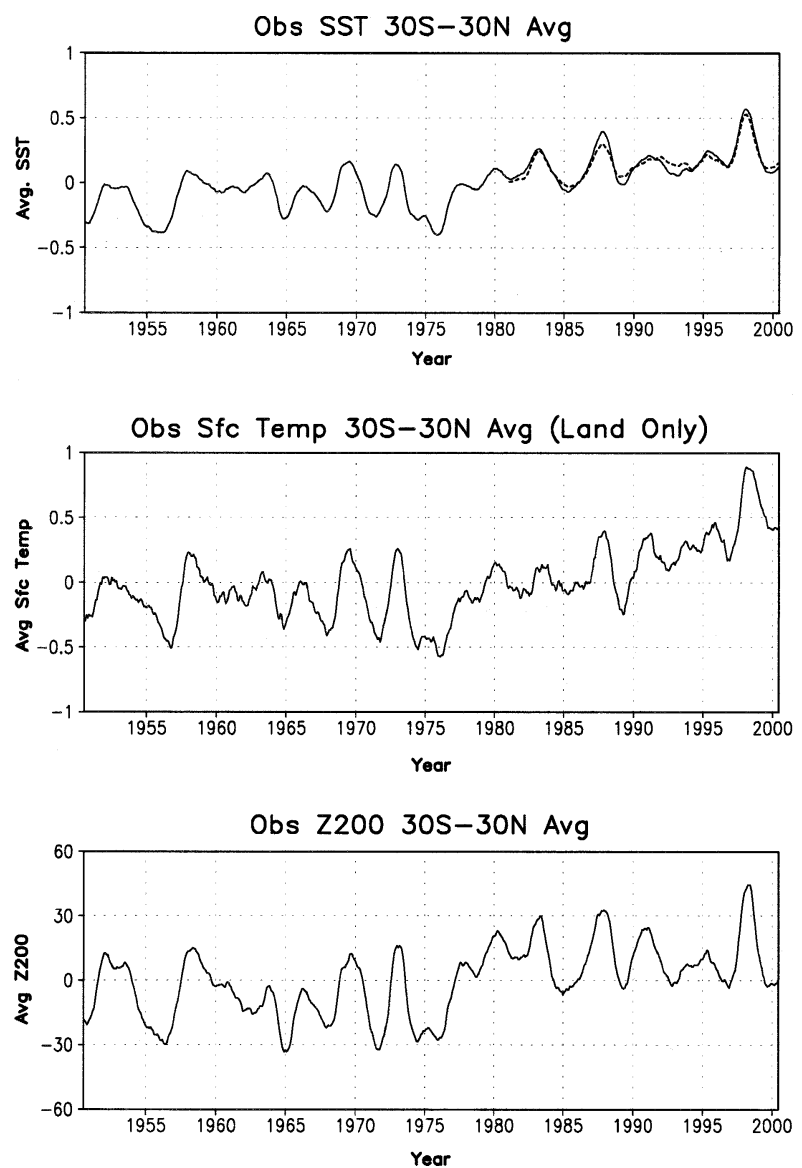

FIG. 1. Temporal evolution of the observed (top) area-averaged sea surface temperature, (middle) area-averaged surface temperature over land, and (bottom) 200-mb height anomalies. Area averages are taken between $30^{\circ} \mathrm{S}$ and $30^{\circ} \mathrm{N}$, and an appropriate land-sea mask is applied for sea surface and land surface temperatures. Time series are smoothed with a 13-month running mean. Units for temperatures are ${ }^{\circ} \mathrm{C}$, and for heights are m. Dashed line in (top) is the observed SSTs based on EOF analysis (see text for details).

with an increase in the tropical SSTs (Mitchell et al. 1987). Such arguments are based on the assumption that with all factors that contribute to air-sea interactions held constant (e.g., surface wind speed, surface stability, etc.), warmer SSTs will lead to an increase in evaporation, and thereby an increase in precipitation. However, an increased global hydrological cycle does not necessarily imply that all regions will experience an increase in rainfall. Mass continuity requires that increased vertical mass transport associated with increased precipitation over some region is compensated by increased descending motion elsewhere, possibly leading to drying trends over the regions of increased descent. This can also lead to a complex spatial structure for the precipitation trends. Given the societal importance of precipitation, it is important to document the geographic distribution of the expected precipitation trend.

In view of the difficulties in estimating precipitation trends from the observed data, precipitation trends are analyzed from atmospheric general circulation model (AGCM) simulations forced with observed SSTs. The analysis focuses on trends over tropical oceans and land masses. We also contrast the trends in precipitation with those of temperature and 200-mb geopotential height and show a distinct difference between the trends over land and ocean. Even over the oceans, trends in precipitation have a more complex spatial structure than other tropical fields and also differ from the trends in the underlying SSTs. The data and model simulations are outlined in section 2 , and the results are presented in section 3. A summary and concluding remarks are given in section 4 .

\section{Data and the AGCM simulations}

Our analysis is based on both observational data and atmospheric general circulation model data. Monthly mean 200-mb observed heights for the 1950-2000 period are obtained from the NCEP-NCAR reanalysis (Kalnay et al. 1996). Monthly mean observed SST for the same period consists of a blended dataset based on two sources. The first constructs global fields during $1950-81$ by projecting the monthly in situ SSTs onto empirical orthogonal functions (Smith et al. 1996). The second is an SST analysis constructed by combining in situ and satellite observations using an optimum interpolation technique (Reynolds and Smith 1994).

Monthly mean observed surface temperature anomalies over land are from the Climate Analysis and Monitoring System's (CAMS) archive of the global network of surface observations maintained at the NCEP (Ropelewski et al. 1985). Monthly mean precipitation data over the land are also obtained from CAMS. These datasets are available on a regular $2.5^{\circ}$ latitude-longitude grid.

Data from ensembles of simulations from two AGCMs are used to complement the observational analysis. These AGCMs are the National Aeronautics and Space Administration (NASA) Seasonal-to-Interannual Prediction Project (NSIPP) AGCM (Bacmeister et al. 2000), and the European Centre for Medium-Range Weather Forecasts (ECMWF)-Hamburg climate model 4.5 (ECHAM4.5) run at the International Research Institute (IRI; Roeckner et al. 1996), and are referred to as NSIPP and ECHAM4.5.

For each AGCM an ensemble of realizations for the 1950-2000 period is available with 9 realizations for NSIPP and 24 realizations for ECHAM4.5. All realizations within the ensemble are forced with the same SST forcing, but differ in their specification of the atmospheric initial conditions. Monthly mean observed SSTs are used to force all simulations. From these AGCM simulations ensemble averages of monthly mean 200-mb heights, surface temperature over land, and precipitation over land and oceans, are used in our analysis. Monthly mean anomalies for the observations and the AGCM simulations are obtained from their respective 
TABLE 1. Temporal anomaly correlations between various areaaveraged variables. All correlations are for the 1950-2000 period and are for the 13-month running means as in the time series shown in Figs. 1-3. Correlation variables are $\mathrm{SFCT}_{0}$ : observed surface temperature over the land; SST: observed sea surface temperature; $Z 200_{0}$ : observed 200-mb heights; SFCT $_{\text {ec }}$ : surface temperature over land for ECHAM4.5 simulations; $\mathrm{SFCT}_{\mathrm{ns}}$ : surface temperature over land for NSIPP simulations; $Z 200_{\mathrm{ec}}$ : 200-mb heights for ECHAM4.5 simulations; $Z 200_{\mathrm{ns}}$ : 200-mb heights for NSIPP simulations; OPREC ${ }_{\mathrm{ec}}$ : precipitation over ocean for ECHAM4.5 simulations; OPREC $_{\mathrm{ns}}$ : precipitation over ocean for NSIPP simulation; LPREC $_{\mathrm{ec}}$ : precipitation over land for ECHAM4.5 simulation; LPREC $_{\mathrm{ns}}$ : precipitation over land for NSIPP simulation; LPREC $_{\mathrm{o}}$ : observed precipitation over land.

\begin{tabular}{|c|c|}
\hline$\left(\mathrm{SFCT}_{\mathrm{o}}, \mathrm{SST}\right)$ & 0.89 \\
\hline$\left(Z 200_{0}, \mathrm{SST}\right)$ & 0.89 \\
\hline$\left(\mathrm{SFCT}_{\mathrm{ec}}, \mathrm{SST}\right)$ & 0.94 \\
\hline$\left(\mathrm{SFCT}_{\mathrm{ec}}, \mathrm{SFCT}_{\mathrm{o}}\right)$ & 0.96 \\
\hline$\left(\mathrm{SFCT}_{\mathrm{ns}}, \mathrm{SST}\right)$ & 0.95 \\
\hline$\left(\mathrm{SFCT}_{\mathrm{ns}}, \mathrm{SFCT}_{\mathrm{o}}\right)$ & 0.91 \\
\hline$\left(Z 200_{\mathrm{ec}}, \mathrm{SST}\right)$ & 0.97 \\
\hline$\left(Z 200_{\mathrm{ns}}, \mathrm{SST}\right)$ & 0.96 \\
\hline$\left(\mathrm{OPREC}_{\mathrm{ec}}, \mathrm{SST}\right)$ & 0.62 \\
\hline$\left(\mathrm{OPREC}_{\mathrm{ns}}, \mathrm{SST}\right)$ & 0.67 \\
\hline$\left(\mathrm{LPREC}_{\mathrm{ec}}, \mathrm{SST}\right)$ & -0.76 \\
\hline$\left(\mathrm{LPREC}_{\mathrm{ns}}, \mathrm{SST}\right)$ & -0.57 \\
\hline$\left(\mathrm{LPREC}_{\mathrm{ec}}, \mathrm{LPREC}_{\mathrm{o}}\right)$ & 0.63 \\
\hline$\left(\mathrm{LPREC}_{\mathrm{ns}}, \mathrm{LPREC}_{\mathrm{o}}\right)$ & 0.57 \\
\hline
\end{tabular}

climatologies for the 1950-2000 period. We should point out that the AGCM simulations do not include any trends in natural (e.g., solar, volcanic, etc.) or anthropogenic (e.g., $\mathrm{CO}_{2}$, etc.) forcings, and therefore any trends in the atmospheric circulation fields are solely due to trends in SSTs.

The analysis focuses on variability within $30^{\circ} \mathrm{S}-30^{\circ} \mathrm{N}$. This choice is consistent with other studies of a similar nature (Soden 2000; Sobel et al. 2002). Results and conclusions do not change for a more restricted definition of the Tropics (e.g., $20^{\circ} \mathrm{S}-20^{\circ} \mathrm{N}$ ).

\section{Results}

SSTs over the tropical oceans have an abrupt upward trend starting around 1976 (Fig. 1, top), a period when many different atmospheric circulation indices also show an abrupt shift (Trenberth and Hurrell 1994). To confirm that SST trends are not due to changes in the SST analysis scheme, SST time series based on empirical orthogonal functions for the post- 1980 period is also shown (Fig. 1, top, dashed curve). SST anomalies based on this analysis closely follow the anomalies based on the optimum interpolation technique, confirming that the SST trend is not an artifact of change in the analysis scheme.

The surface temperatures over land (hereafter referred to as SFCT) also trend toward warmer values in the observations (Fig. 1, middle). Superimposed on these trends are the interannual variations related to ENSO. A comparison of tropicwide SSTs and SFCTs indicates an in-phase relationship between the two time series

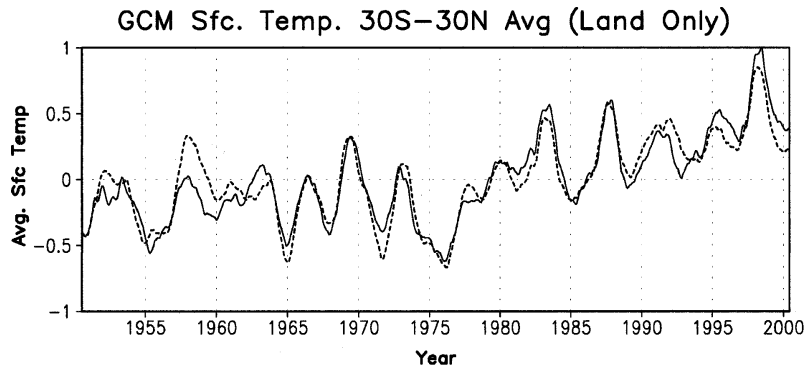

Z200 30S-30N Avg

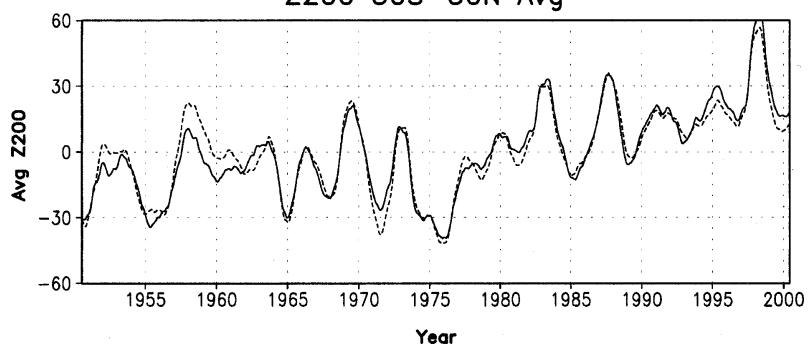

FIG. 2. Temporal evolution of (top) area-averaged land surface temperature and (bottom) 200-mb height anomalies for ECHAM4.5 (solid curve) and NSIPP (dashed curve) AGCM simulations. As for Fig. 1, area averages are taken in between $30^{\circ} \mathrm{S}$ and $30^{\circ} \mathrm{N}$ and an appropriate land-sea mask is applied for land surface temperatures. Time series are smoothed with a 13-month running mean. Units for temperatures are ${ }^{\circ} \mathrm{C}$, and for heights are $\mathrm{m}$.

with a temporal anomaly correlation of 0.89 (see Table 1 for various anomaly correlations). In other words, surface temperature variability over tropical land is coincident with SST variability over the tropical oceans.

Variations similar to the SST and SFCT also occur in the observed 200-mb tropical heights (Fig. 1, lower), including a shift toward higher heights around 1976. This increase in heights is indicative of warmer tropical tropospheric temperatures and accompanies the variations in SST. The temporal anomaly correlation between 200-mb height and SST time series in Fig. 1 is also 0.89 . That the variations in the SFCT and $200-\mathrm{mb}$ heights are forced by the SSTs is demonstrated from the analysis of AGCM simulations.

The time series of the simulated SFCT and 200-mb heights from the ACGM simulations show good temporal agreement with the observed trends (Fig. 2). Indeed, the temporal correlations for SFCT and 200-mb heights between the AGCM simulations and observations exceed 0.9. Because the only external forcing in the AGCM simulations is from the observed SSTs, it implies that the trends in SFCT and 200-mb height are forced by the SST. One interesting point to note is that trends in the 200-mb heights for the AGCM simulations are more similar to the trends in the tropical SST forcing (Fig. 1) and in the AGCM-simulated land temperature than a similar comparison in the observations. The reasons for this discrepancy for the observed 200-mb heights, which show an abrupt shift toward higher heights around 1976 but no increasing trend afterward, 


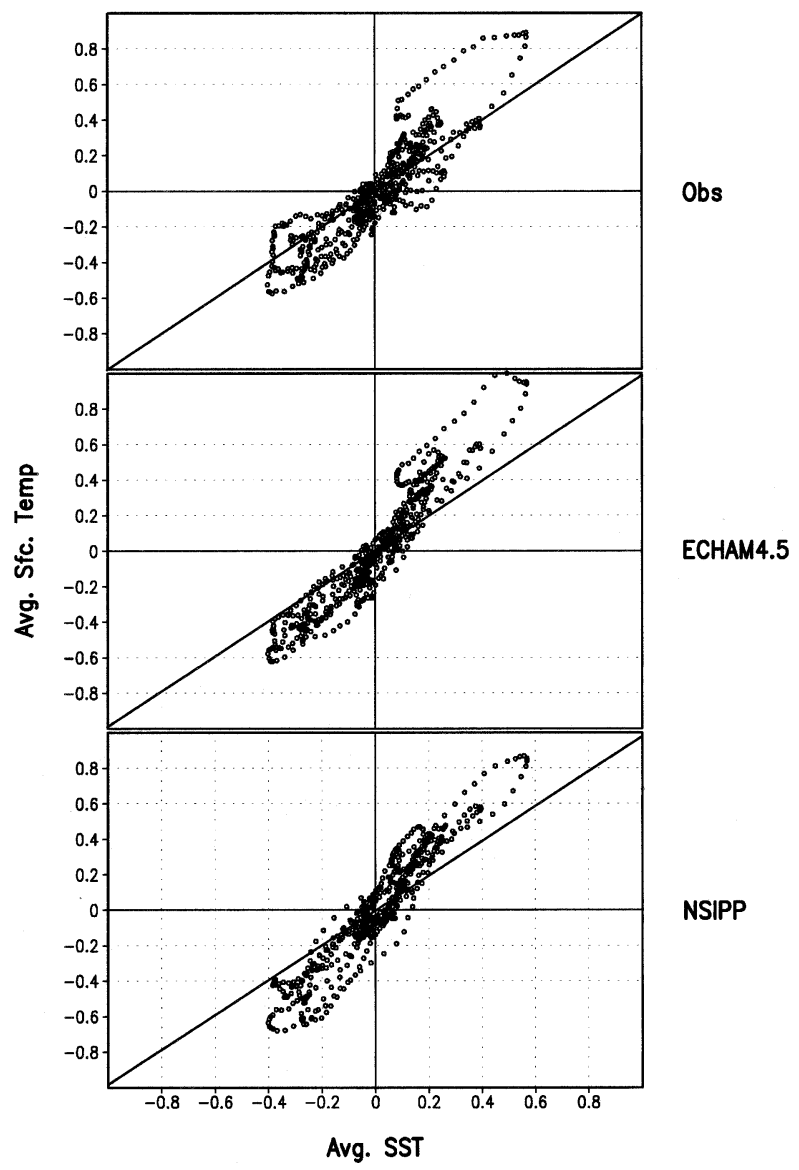

FIG. 3. Scatterplot of area-averaged sea surface temperatures $(x$ axis) and land surface temperatures ( $y$ axis) for (top) observations, (middle) ECHAM4.5 simulations, and (bottom) NSIPP simulations. Units are ${ }^{\circ} \mathrm{C}$, and scatterplots are based on the 13-month running mean time series shown in Figs. 1 and 2.

is not clear. It is possible that changes in the observing system and their impact on the reanalysis may be responsible for this behavior (Trenberth et al. 2001).

The influence of interannual variations in tropical Pacific SSTs on the tropical tropospheric temperatures is well documented. For example, during warm ENSO events, warm tropospheric anomalies spread across the entire Tropics (Newell and Weare 1976; Pan and Oort 1983; Yulaeva and Wallace 1994; Kumar and Hoerling 2003). This pattern of almost uniform warming of the tropical atmosphere during warm ENSOs is consistent with tropical wave dynamics. The physics of this linkage on the ENSO time scale is suggested by the in-phase relationship between the 200-mb heights and SSTs. It is possible that similar mechanisms also act on the longer time scales, linking the trends between the 200-mb height and SST in the model simulations as well as in the observations.

The physical mechanism for the in-phase relationship between SFCT and SST anomalies may be related to the response of the land surface to the tropical tropo-
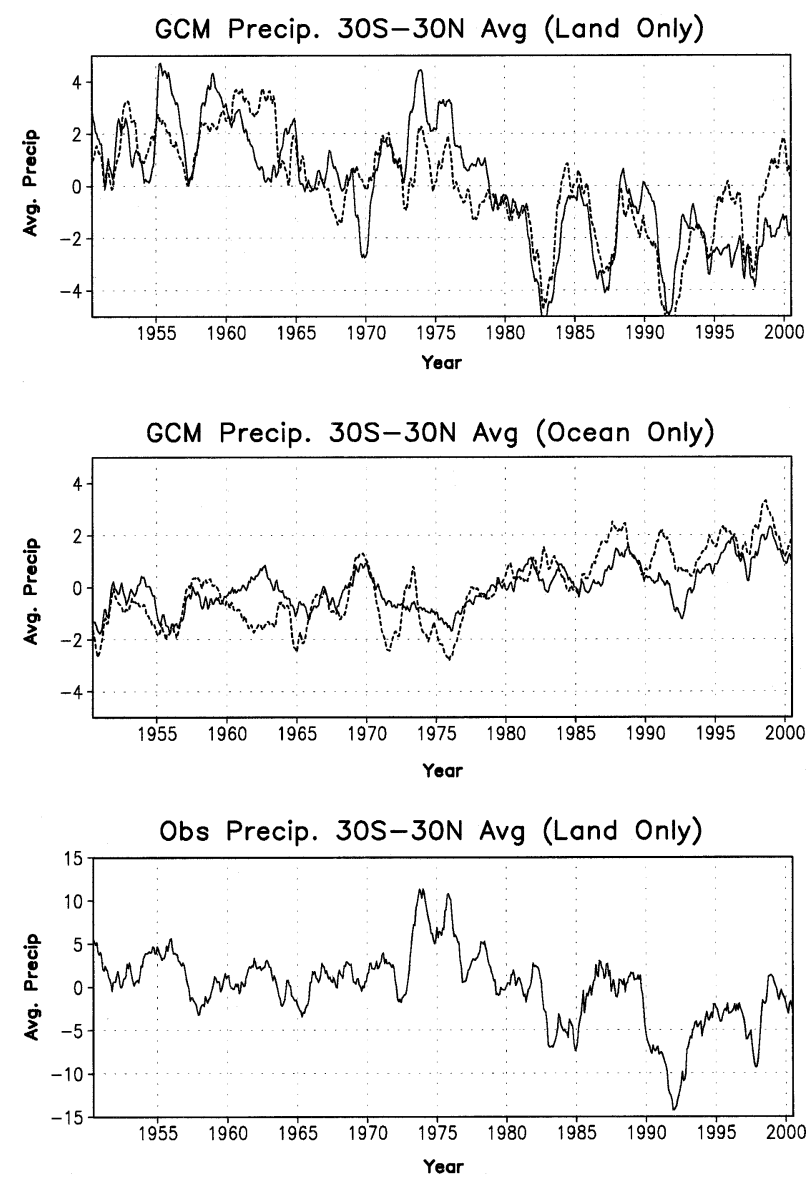

FIG. 4. Temporal evolution of precipitation (top) over land and (middle) over ocean for AGCM simulations; (bottom) the area-averaged observed precipitation over land. Units are $\mathrm{mm}$ month $^{-1}$. Area averages are taken between $30^{\circ} \mathrm{S}$ and $30^{\circ} \mathrm{N}$, and an appropriate landsea mask is applied. Time series are smoothed with a 13-month running mean. In (top) and (middle) dark curves represent ECHAM4.5 simulations and dashed curves represent NSIPP simulations.

spheric temperature anomalies due to anomalous SSTs. For example, Yulaeva and Wallace (1994) hypothesized that the tropospheric temperature anomalies in the tropical latitudes due to ENSO, which tend to be spatially homogenous, could be conveyed to the underlying remote tropical oceans by thermodynamic relaxation. More recently, Chiang and Sobel (2002), using a single column model for the tropical atmosphere, also demonstrated the possibility of such a process. A similar mechanism can also lead to surface temperature warming over the tropical land areas in response to warmer SSTs, leading to an in-phase relationship between the SFCT and SST. Further, since the heat capacity of land is smaller than the oceans, adjustment of surface temperatures over land would be quicker than that of SSTs documented in many studies (e.g., see Klein et al. 1999).

Another possible mechanism for the in-phase relationship between SFCT and SST could be a decrease in cloudiness over the tropical land regions owing to the atmospheric subsidence induced by the warmer 


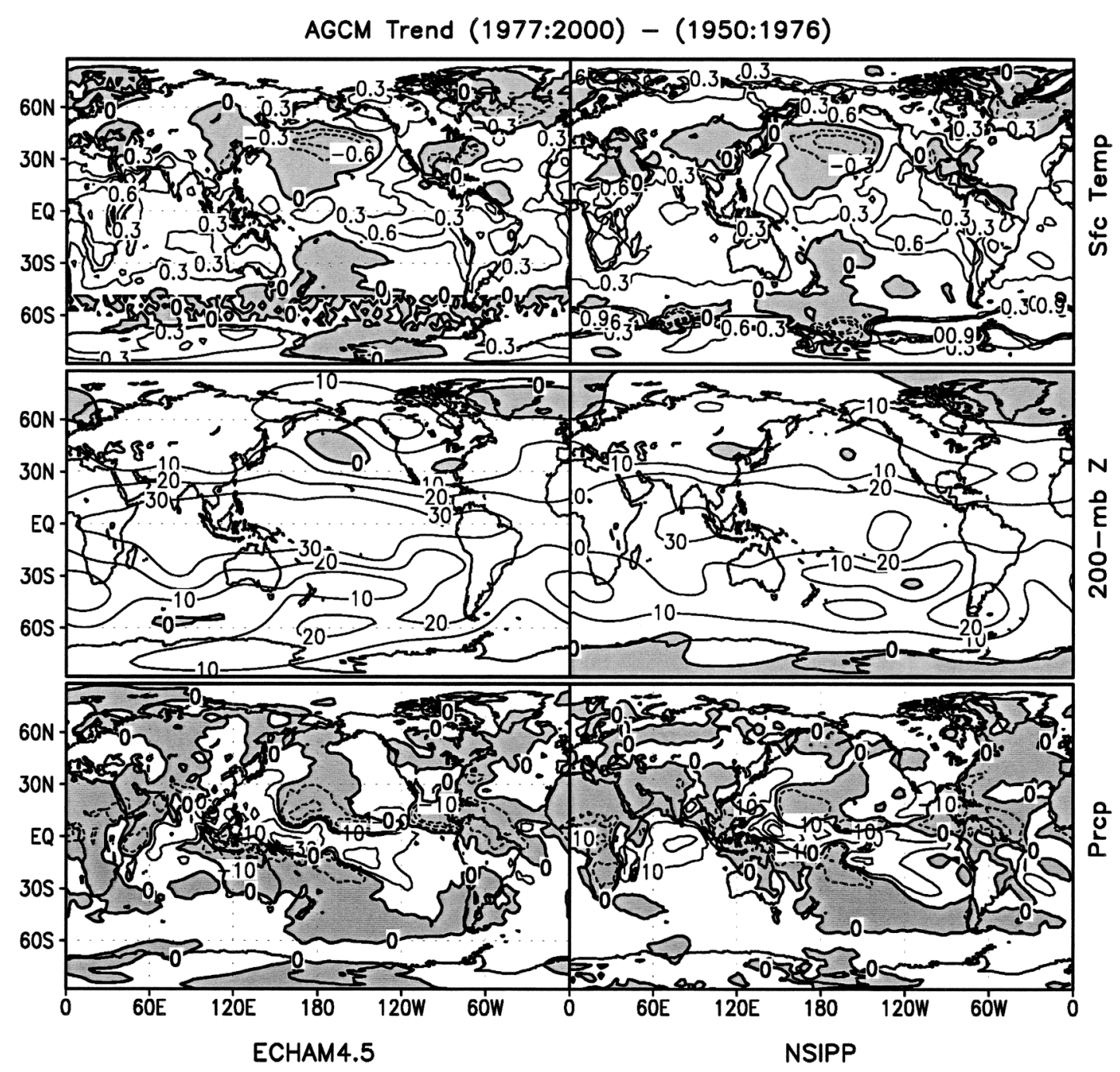

FIG. 5. Difference in time means for (top) surface temperatures, (middle) 200-mb heights, and (bottom) precipitation for AGCM simulations. Differences are between the time mean for the 1977-2000 period and for the 1950-76 period. Results for (left) ECHAM4.5 simulations and (right) NSIPP simulations. Negative values are shaded. Units are ${ }^{\circ} \mathrm{C}$ for temperature, $\mathrm{m}$ for $200-\mathrm{mb}$ height, and $\mathrm{mm} \mathrm{month}^{-1}$ for precipitation.

SSTs. This decrease in cloudiness would also increase surface temperature, via an increase in the surface shortwave insolation. Further, a reduction in precipitation due to atmospheric subsidence would also lead to reduction in the soil moisture, which could be an additional factor responsible for the increase in the land surface temperatures. Indeed, it is interesting to note that both in the observations and the AGCM simulations (see Fig. 3), the amplitude of variability in SFCT is larger than the amplitude of variability in SSTs. Amplified response over the land, therefore, could be due to constructive interference of multiple causes, which can lead to an increase in land temperature.

We next analyze the trends in the oceanic and land precipitation. In the model simulations there is a welldefined quasilinear in-phase relationship between the SFCT and SSTs (Fig. 3), as well as between the 200- mb heights and SSTs (not shown), which is not replicated by the precipitation over the tropical oceans or over the tropical land (see Fig. 4 and Table 1). In fact, precipitation over the tropical land is out of phase with SSTs, and the temporal anomaly correlation is negative for both AGCMs (see Table 1). For the ocean points alone, the temporal anomaly correlation between the AGCM simulated precipitation and SST is positive. However, it is much lower than that for the 200-mb tropical heights as a results of the much more complicated spatial structure of the precipitation changes.

Apart from weaker correlations, both AGCMs show a distinct shift in area-averaged precipitation anomalies over the tropical land and oceanic areas around 1976. However, unlike SST and SFCT, the shift and associated trends are in opposite directions over the ocean and land areas. Over the ocean the area-averaged precipitation 


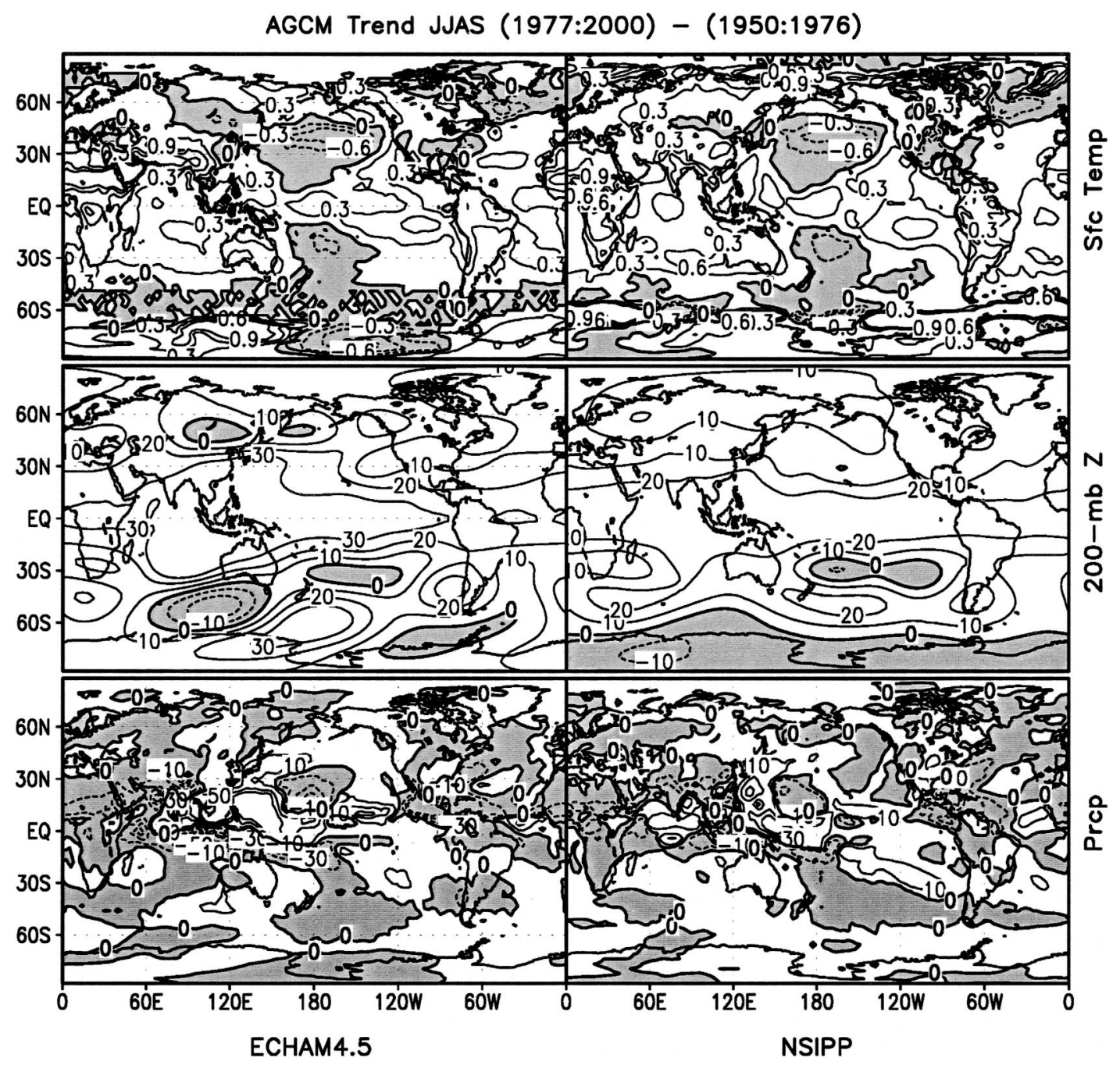

FIG. 6. Same as Fig. 5, but for differences between time averages for Jun-Sep 1977-2000 and for Jun-Sep 1950-76.

increases, while area-averaged precipitation over the tropical land has a downward trend. The observed precipitation estimates over the tropical land areas also exhibit a trend similar to the precipitation in the AGCM simulations (Fig. 4), that is, a reduction after 1976. The correlation between the AGCM and the observed precipitation time series over land, given in Table 1, are positive. Note that over the tropical land areas, the trends in the SFCT for both the observations and the AGCM simulations are opposite to the trend in the precipitation.

A crude estimate of the trend over the 1950-2000 period is approximated by the difference between the mean climate over the 1977-2000 period and the mean climate over the $1950-76$ period. The spatial patterns of trends in surface temperature, 200-mb heights, and precipitation are very similar between the two AGCMs (Fig. 5). Both AGCMs show warmer surface temperatures in recent decades over the tropical land areas almost everywhere. Similarly, 200-mb heights shift to- ward higher values, the pattern of which is spatially homogenous in the tropical latitudes.

The spatial structure of the precipitation trend has a much more complex structure. Most notably, while the tropical oceanic rainfall has increased on the whole, consistent with the increase in tropical SSTs, the precipitation over the tropical land regions shows a general decrease. A similar decrease in the observed rainfall also occurs (Fig. 8, top). Although there is limited rainfall data over ocean areas with which to compare the AGCM trends, the results shown over the western Pacific are qualitatively similar to those reported by Morrissey and Graham (1996) using tropical Pacific island stations. A comparable result has been found with other AGCMs also (e.g., Graham 1995). The qualitative agreement between all of these AGCM simulations suggests that the trends in the climate are consistent with the trends in surface forcing and are not a manifestation of some internal atmospheric variability; although, it 


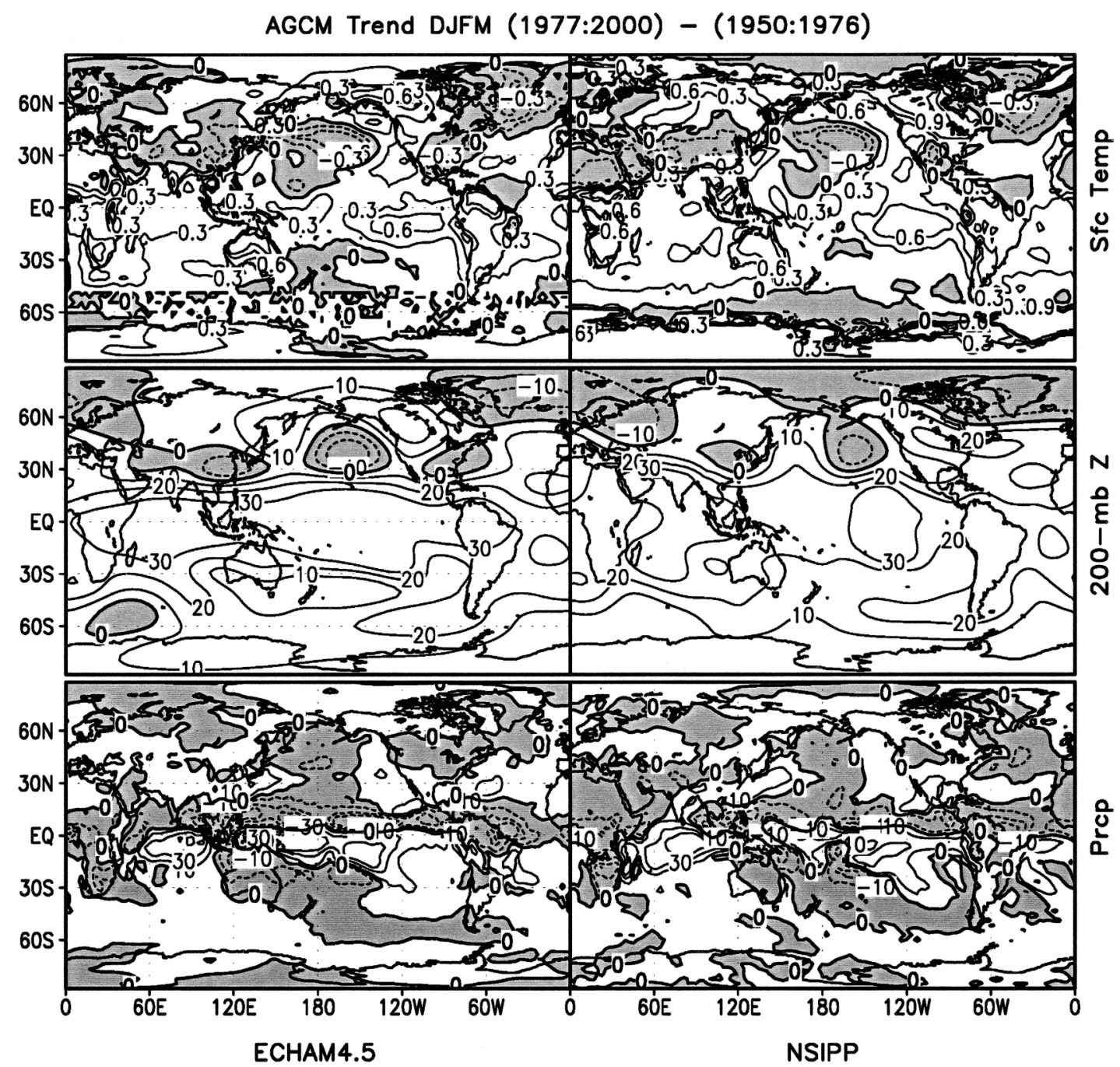

FIG. 7. Same as Fig. 6, but for Dec-Mar time average.

does not address the origin of the trends in surface forcing.

We next break down trends in the annual mean into trends in the boreal summer (defined as the June-Septmeber average), and boreal winter (defined as December-March average) seasons separately. This analysis is particularly useful for the tropical rainfall trends because dramatic changes in the monsoonal circulation lead to large seasonal variations in precipitation climatology. Trends computed for the boreal summer are shown in Fig. 6, and for boreal winter in Fig. 7.

The spatial pattern of the simulated tropical surface temperature trends does not show appreciable seasonality. This is also true for the tropical 200-mb height trends. An interesting point to note is that $200-\mathrm{mb}$ height trend in the extratropical latitude shows a marked seasonality with trends being largest and more zonally asymmetric during the respective hemisphere's boreal winter. This is consistent with the analysis of seasonality of atmospheric response to SST anomalies in the tropical eastern Pacific on an interannual time scale (Kumar et al. 2003).

Seasonality in the simulated tropical precipitation trends is more interesting. For the boreal summer, the largest trend in precipitation is mainly concentrated over the regions of summer monsoon in Southeast Asia and northern Africa, along with the Caribbean. For both AGCM simulations, precipitation over the land region associated with the summer monsoon experiences a reduction, whereas rainfall over the oceanic region generally has a positive trend. During the boreal winter, the reduction in rainfall over the tropical land masses shifts southward to the regions of large climatological precipitation over southern Africa, Australia, and Amazonia (Fig. 7). A similar seasonal shift is also found in the observed precipitation estimates over the land (see Fig. 8, middle and lower panels).

Over the tropical oceans, where the AGCMs show a 
Obs Prcp Trend (1977:2000) - (1950:1976)
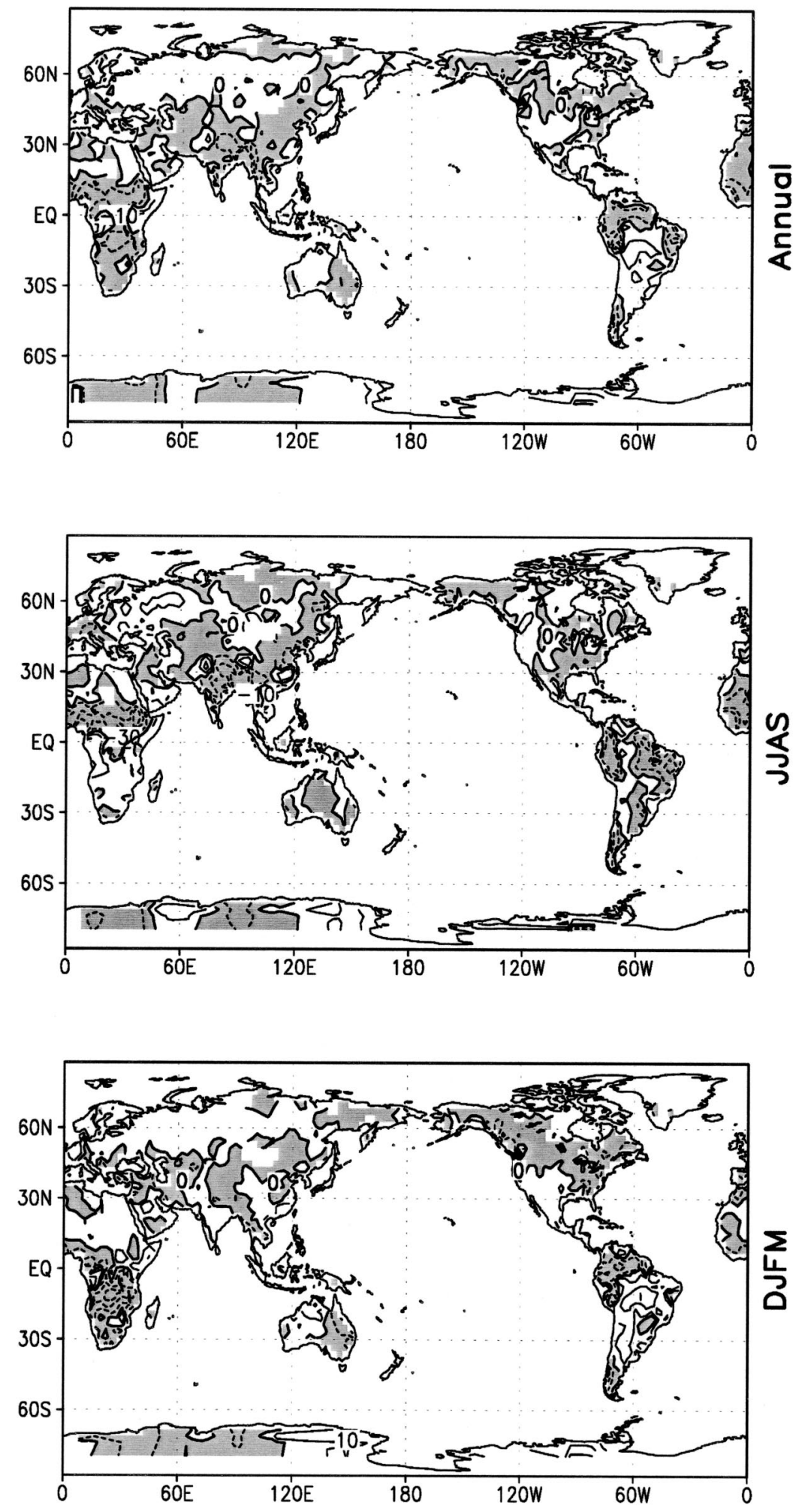

FIG. 8. Difference in time means for the observed precipitation over land. Differences are between (top) annual time mean for 1977-2000 and for 1950-76, (middle) time mean for Jun-Sep between 1977-2000 and 1950-76, and (bottom) time mean for Dec-Mar between 1977-2000 and 1950-76. Negative values are shaded. Units are mm month ${ }^{-1}$. 
net increase in rainfall, the spatial structure of the trends is different from the imposed SST forcing. Whereas the SST is warmer throughout the Tropics, precipitation trends in the tropical oceans also show regions of decrease. This is due to the fact that the increased vertical mass transport associated with increased convection over some regions has to be balanced by the increased descending motion elsewhere, leading to drying over the regions of increased descent. Other studies have also shown that the local precipitation response is highly nonlinear ( $\mathrm{Su}$ et al. 2003), and warmer SSTs are not always associated with positive precipitation anomalies.

It is difficult to conclude the exact balance of physical mechanisms leading to the spatial rainfall trend pattern. This issue cannot be answered confidently using the models either because in AGCMs SSTs are prescribed, while it is widely believed that SST variability outside the tropical eastern/central Pacific is at least partially driven by atmospheric forcing (e.g., Klein et al. 1999; Kumar and Hoerling 1998). This physical inconsistency could potentially lead to an unrealistically strong rainfall response over the warming tropical oceans outside the tropical Pacific, in particular over the Indian Ocean where mean temperatures are already high enough to support convection. However, some suggestion of the precipitation response over the oceans is obtained from the AGCMs. In particular, the agreement in two independent AGCMs with the observed rainfall trends over land lends credibility to the models' ability to respond to increasing SSTs in the Tropics.

Circulation trends in the AGCMs also give some clues as to how the atmosphere's response to increasing SSTs can lead to drier conditions over the tropical land. The circulation changes in the ECHAM4.5 model appear as a modification of the dominant tropical circulation cells (Figs. 9 and 10). As one might expect, rainfall patterns equatorward of $40^{\circ}$ are highly correlated with the vertical motion field. The magnitude of the spatial correlations between the pattern of rainfall changes and vertical motion changes exceeds 0.9 for both the JJAS and DJFM seasons. The changes in the vertical motion field result from changes in midtropospheric latent heat release due to convergence of relatively moister air (not shown) as well as changes in low-level winds responding to modified SST gradients, particularly in the meridional direction. The change in tropical circulation is most evident in the meridional direction as an intensification of the meridional overturning, or Hadley circulation. However, changes in the zonal overturning, or Walker circulation, can also be seen. In addition, Gilltype responses (Gill 1980) arise from increased local equatorial heating evidenced by descending motion offequator to the west of the heating. These circulation changes lead to both enhancements and shifts of mean convective areas, impacting regional "wet seasons" over land.

During June-September the seasonal monsoons dominate the tropical climate system. At this time of year, the most substantial atmospheric response to the changes in SST involves the Asian monsoon. Convective activity in the western Pacific north of the equator, the South China Sea, and over the Bay of Bengal has increased $10 \%-50 \%$ in the $1977-2000$ period relative to the 50-yr mean (Fig. 9). The increased convection draws the seasonal rainfall from land toward the ocean. The southerlies over southern and eastern Asia have decreased and the subsidence over that area has increased leading to drier conditions. In the southwestern Pacific, the South Pacific convergence zone (SPCZ), although weak at this time of year, shows some suggestion of an equatorward and eastward shift. The southerly winds along the south flank of the SPCZ appear much more elongated into the South Pacific, leading to a contraction of the southwestern edge of the subtropical high to the west of South America. Variations in the zonal circulation cells are also apparent at this time of year (Fig. 9c). Increased upward motion over Indonesia, and to a lesser extent over the central Pacific, is partly compensated by downward motion over Central America and northern South America and also over Africa and the western Indian Ocean.

During the December-March season the eastward and equatorward shift of the SPCZ is even stronger (Fig. 10). The combination of the strengthened Hadley cell in the southwestern Pacific and the Gill-type response to the increased near-equatorial heating in the western Pacific causes enhanced subsidence, particularly over northern Australia. Increased upward motion in the western Pacific also modifies the Walker circulation, leading to more subsidence over northern South America (Fig. 10c). A second strong zonal overturning cell has developed over the Indian Ocean with strong rising motion over the central Indian Ocean and descending motion over Indonesia. The increased latent heating over the central Indian Ocean appears to be responsible for a Gill-type response over southern Africa, negatively impacting their rainy season, and to a lesser extent over the Middle East.

Given the qualitative consistency between AGCM and observed rainfall trends in regions where they can be compared, the documented circulation trends seen in the model are reasonable and should provide a conceptual framework for examining observed atmospheric circulation data.

\section{Summary and discussions}

From the AGCM simulations forced with the observed SSTs, it was demonstrated that the trends in tropical precipitation have a different characteristic than the trends in the surface temperatures and the tropical 200$\mathrm{mb}$ heights. For all tropical ocean points taken together, SSTs and precipitation trends are in the same direction and both have increased in recent decades. On the other hand, for tropical land points alone the trends are in the opposite direction with precipitation showing a de- 
ECHAM4.5 : JJAS

(a) Time mean omega $(500 \mathrm{mb}) \& \vee(1000 \mathrm{mb})$

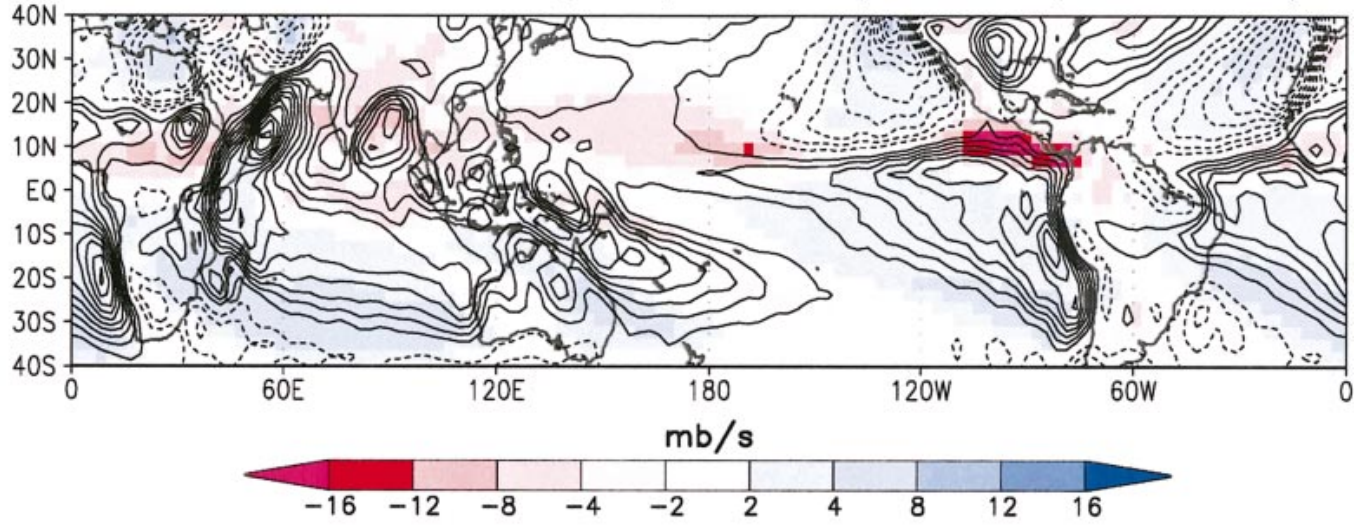

(b) Change in omega $(500 \mathrm{mb}) \& \vee(1000 \mathrm{mb})$

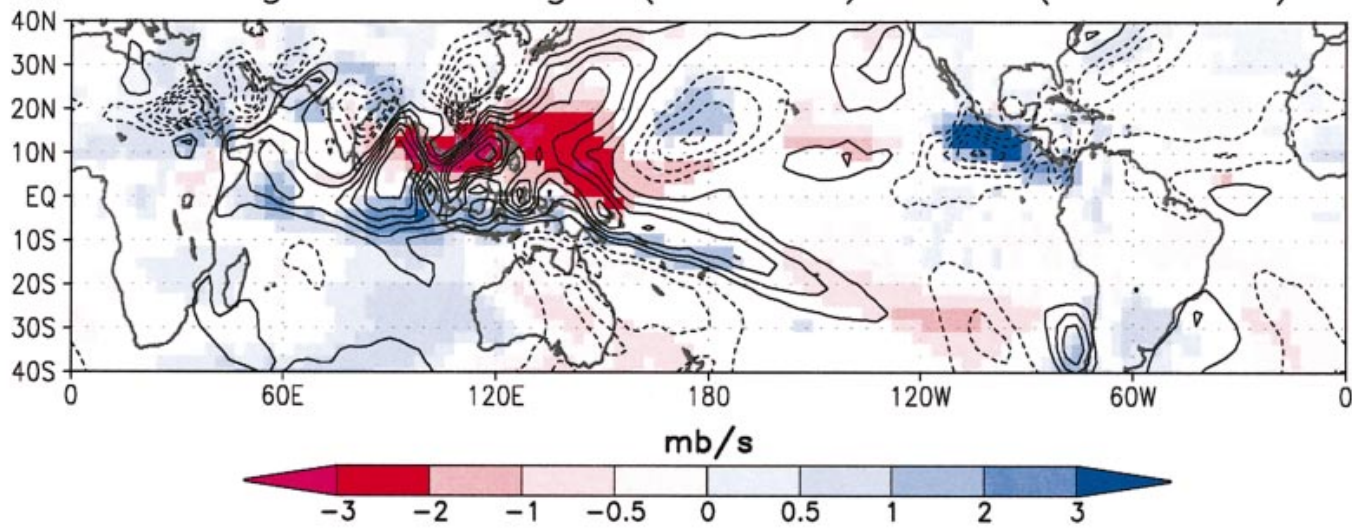

(c)

Changes in Zonal Overturning Circulation

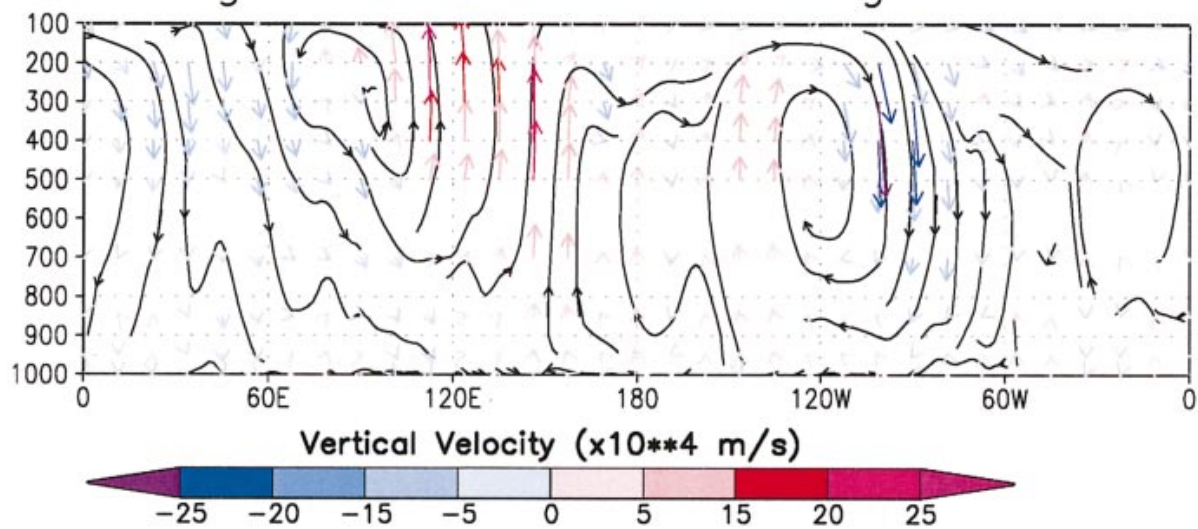

FIG. 9. Atmospheric circulation patterns for the Jun-Sep season as simulated by the ECHAM4.5 AGCM. (a) Time mean (1950-2000) fields of vertical motion at $500 \mathrm{mb}$ (shading: red colors indicate ascent and blue colors indicate descent) and low-level meridional winds at $1000 \mathrm{mb}$ (contours: contour interval is $1 \mathrm{~m} \mathrm{~s}^{-1}$ and 0 contour is suppressed). (b) Difference in time means for vertical motion (shading: note only differences statistically significant at $95 \%$ confidence or better are shaded) and low-level meridional winds (contours: contour interval is 0.2 and 0 contour is suppressed). Differences are between time mean for 1977-2000 and for 1950-76. (c) Differences in time means for zonal overturning circulation $(u, w)$, averaged $10^{\circ} \mathrm{S}-10^{\circ} \mathrm{N}$. The vertical velocity has been amplified for better visualization. Streamlines indicate circulation cells. Vectors further indicate strength and direction of flow in the plane; colors assigned to arrows indicate the magnitude and sign of the vertical velocity. 


\section{ECHAM4.5 : DJFM}

(a) Time mean omega $(500 \mathrm{mb}) \& \vee(1000 \mathrm{mb})$

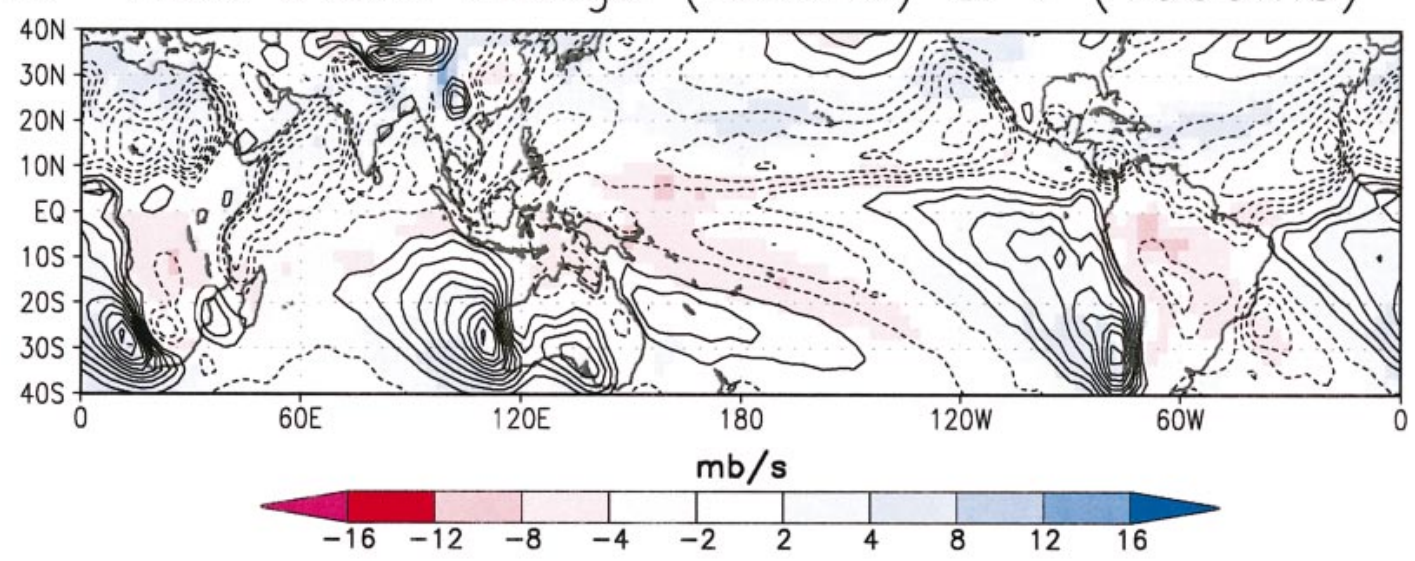

(b) Change in omega $(500 \mathrm{mb}) \& v(1000 \mathrm{mb})$

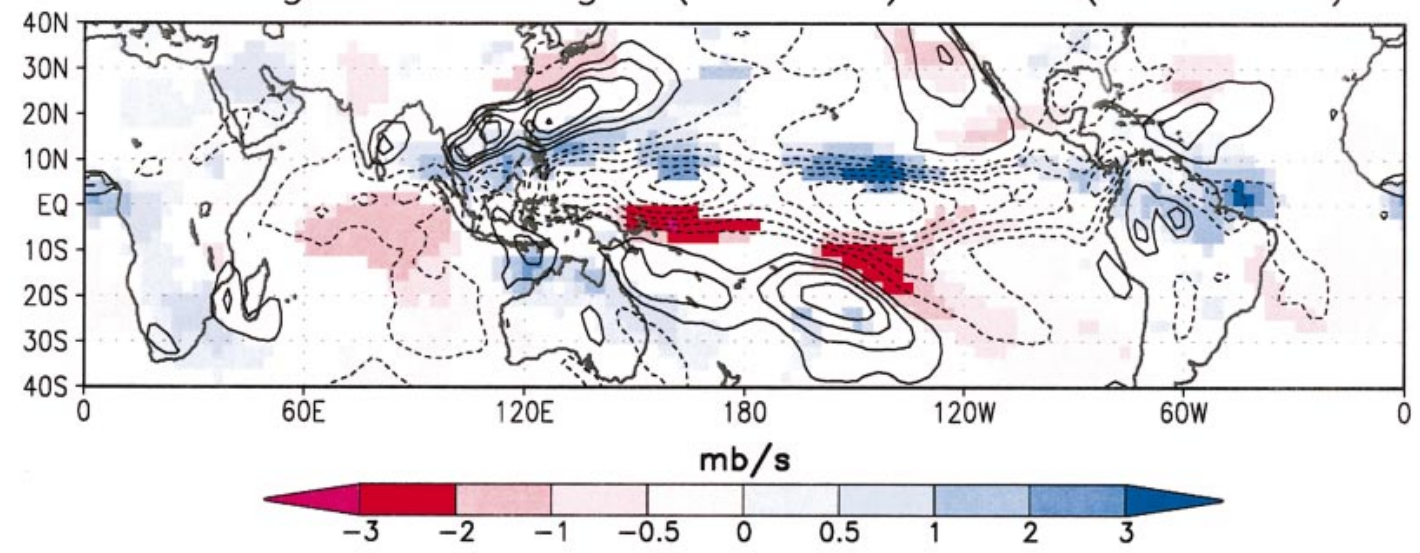

(c)

Changes in Zonal Overturning Circulation

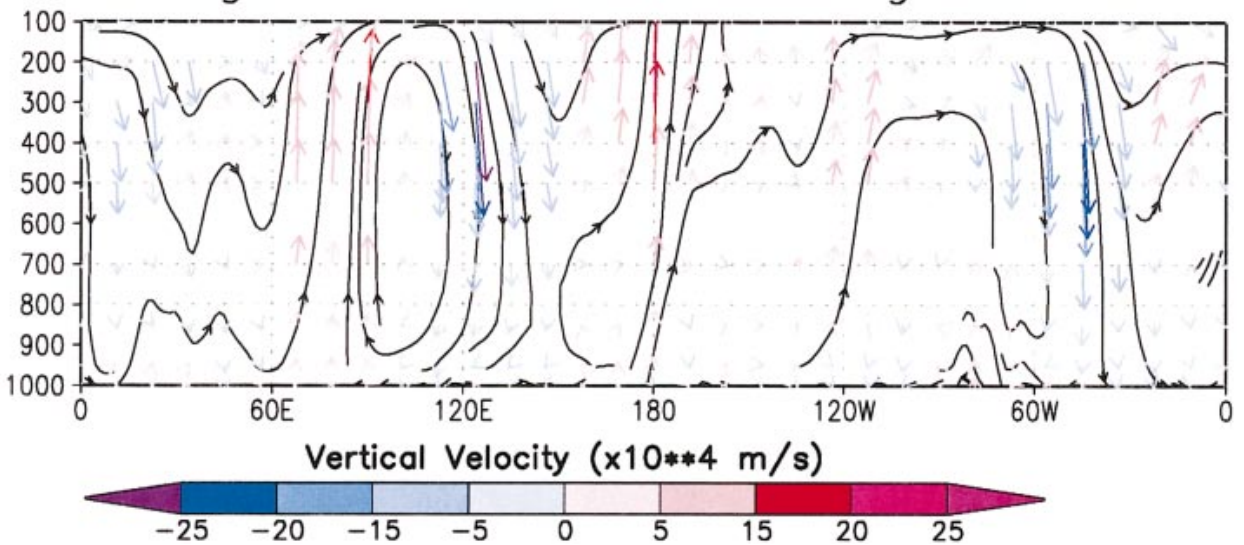

FIG. 10. Same as Fig. 9, but for the Dec-Mar season. 
crease. Similarly, whereas SST and land surface temperature trends are similar, precipitation trends over the land and ocean points are opposite. The complex spatial pattern of rainfall is consistent with increasing SSTs and the constraint of mass continuity across horizontal surfaces such that some regions experience an increase in precipitation while others experience decreases.

It is evident that there is a quasilinear in-phase relationship between the SST and tropical averaged 200$\mathrm{mb}$ heights, which are a good proxy for the tropospheric average temperatures. However, such a relationship between averaged SSTs and precipitation is not strong. This is due to the cancellation between the positive and the negative precipitation anomalies, the origin of which is related to the mass continuity across horizontal surfaces. In other words, an increase in precipitation and associated vertical mass transport over some geographical region has to be balanced by an increased descending motion in the surrounding areas, leading to a reduction in precipitation. It is not clear what fraction of the decreasing trend over the tropical land is because of the enhancement of the tropical circulation cells, with intensification of the descending branch located over the tropical land regions, and what fraction may be due to the contribution from the positive feedback from land surface processes. However, the AGCM results strongly suggest that modification of the tropical circulation cells does figure significantly in the rainfall trends.

Finally, we reiterate that over tropical land regions, the decreasing precipitation trend in recent decades occurs in tandem with an increase in surface temperatures. The combined societal influence of these is possibly much worse than the influence of either one of the trends taken alone.

Acknowledgments. Support offered by NOAA's Climate Dynamics and Experimental Prediction Program is greatfully acknowledged. We would also like to thank two anonymous reviewers for their constructive and insightful comments.

\section{REFERENCES}

Bacmeister, J. T., P. J. Pegion, S. D. Schubert, and M. J. Suarez, 2000: An atlas of seasonal means simulated by the NSIPP 1 atmospheric GCM. Vol. 17. NASA Goddard Space Flight Center Tech. Memo. 104606, 194 pp.

Chiang, J. C. H., and A. S. Sobel, 2002: Tropical tropospheric temperature variations caused by ENSO and their influence on the remote tropical climate. J. Climate, 15, 2616-2631.

Gill, A. E., 1980: Some simple solutions for heat-induced tropical circulation. Quart. J. Roy. Meteor. Soc., 106, 447-462.

Graham, N. E., 1995: Simulation of recent global temperature trends. Science, 267, 666-671.
Hoerling, M. P., and A. Kumar, 2002: Atmospheric response patterns associated with tropical forcing. J. Climate, 15, 2184-2203.

Huffman, G. J., and Coauthors, 1997: The global precipitation climatology project (GPCP) combined precipitation dataset. Bull. Amer. Meteor. Soc., 78, 5-20.

Kalnay, E., and Coauthors, 1996: The NCEP/NCAR 40-Year Reanalysis. Bull. Amer. Meteor. Soc., 77, 437-471.

Klein, S., B. J. Soden, and N.-C. Lau, 1999: Remote sea surface temperature variations during ENSO: Evidence for a tropical atmospheric bridge. J. Climate, 12, 917-932.

Kumar, A., and M. P. Hoerling, 1998: Specification of regional sea surface temperatures in atmospheric general circulation model simulations. J. Geophys. Res., 103 (D8), 8901-8907.

— and _ 2003: The nature and causes for the delayed atmospheric response to ENSO. J. Climate, 16, 1391-1403.

—, S. D. Schubert, and M. S. Suarez, 2003: Variability and predictability of 200-mb seasonal mean heights during summer and winter. J. Geophys. Res., 108, 4169, doi:10.1029/2002JD002728.

Mitchell, J. F. B., C. A. Wilson, and W. M. Cunnington, 1987: On $\mathrm{CO}_{2}$ climate sensitivity and model dependence of results. Quart. J. Roy. Meteor. Soc., 113, 293-332.

Morrissey, M. L., and N. Graham, 1996: Recent trends in rain gauge precipitation measurements from the tropical Pacific: Evidence for an enhanced hydrologic cycle. Bull. Amer. Meteor. Soc., 77, $1207-1219$.

Newell, R. E., and B. C. Weare, 1976: Factors governing tropospheric mean temperature. Science, 194, 1413-1414.

Pan, Y. H., and A. H. Oort, 1983: Global climate variations connected with sea surface temperature anomalies in the eastern equatorial Pacific ocean for the 1958-73 period. Mon. Wea. Rev., 111, $1244-1258$.

Reynolds, R. W., and T. M. Smith, 1994: Improved global sea surface temperature analysis using optimum interpolation. J. Climate, 7, 929-948.

Roeckner, E., and Coauthors, 1996: The atmospheric general circulation model ECHAM4: Model description and simulation of present-day climate. Max Planck Institut für Meteorologie Rep. 218, $90 \mathrm{pp}$.

Ropelewski, C. F., J. E. Janowiak, and M. S. Halpert, 1985: The analysis and display of real time surface climate data. Mon. Wea. Rev., 113, 1101-1106.

Sardeshmukh, P., 1993: The baroclinic chi problem and its application to the diagnosis of atmospheric heating rates. J. Atmos. Sci., 50, 1099-1112.

Smith, T. M., R. W. Reynolds, R. E. Livezey, and D. Stokes, 1996: Reconstruction of historical sea surface temperatures using empirical orthogonal functions. J. Climate, 9, 1403-1420.

Sobel, A. H., I. M. Held, and C. S. Bretherton, 2002: The ENSO signal in tropical tropospheric temperature. J. Climate, 15, 27022706.

Soden, B. J., 2000: The sensitivity of the tropical hydrological cycle to ENSO. J. Climate, 13, 538-549.

Su, H., J. D. Neelin, and J. E. Meyserson, 2003: Sensitivity of tropical tropospheric temperature to sea surface temperature forcing. $J$. Climate, 16, 1283-1301.

Trenberth, K. E., and J. W. Hurrell, 1994: Decadal atmosphere-ocean variations in the Pacific. Climate Dyn., 9, 303-319.

- G. Branstator, G. W. Karoly, A. Kumar, N.-C. Lau, and C. Ropelewski, 1998: Progress during TOGA in understanding and modeling global teleconnections with tropical sea surface temperatures. J. Geophys. Res., 103 (C7), 14 291-14 324.

_ D. P. Stepaniak, J. W. Hurrell, and M. Fiorino, 2001: Quality of reanalyses in the Tropics. J. Climate, 14, 1499-1510.

Yulaeva, E., and J. M. Wallace, 1994: The signature of ENSO in global temperature and precipitation fields derived from the microwave sounding unit. J. Climate, 7, 1719-1736. 